die Chesebrough-Vaseline sich und die Schwefelsäure augenblicklich schwärzt.

Was die zweite Probe, die Natriumprobe, anbetrifft, so waren alle von mir untersuchten und im Vorhergehenden erwähnten Paraffina liquida und solida und alle Vaselinesorten in geringem Grade durch sauerstoffhaltige Produkte verunreinigt, da bei allen ohne Ausnahme die blanke Oberfläche des Natriummetalls, wenn auch nur in geringem Maasse, ein mattes Aussehen annahm, obgleich ich bei jedem Versuche die Vorsicht beobachtete, dass ich die betreffende Substanz stets erst 2-3 Stunden im Wasserbade erhitzte, um ja alle otwa absorbirt gewesenen Luftbläschen auszutreiben.

Freie Säure, die sich beim Auskochen mittelst Weingeist durch eine Prüfung der Reaction desselben mit blauem Lackmusjapier zu erkennen geben wiirde, konnte ich in keinem der Präparate nachweisen.

Bezüglich der Schwefelsäureprobe des Paraffinum liquidum und solidum ist viel für und gegen gesprochen worden; Prof. Fl ü ckiger ermässigte endlich die Forderung dahin:

"Auf das mehr oder weniger dieser Braunfärbung kommt wenig an, ob dieselbe bei $95^{\circ}$ oder bei $65^{\circ}$ im Laufe eines Tages oder nach einigen Viertelstunden eintritt, bedeutet nicht viel." Dieser Anforderung genügen die meisten Paraffina liquida und solida des Handels, während die Probe der Pharmakopöe zu scharf erscheint, wenn es auch gelang, einige Paraffine so rein darzustellen.

\title{
Wie verschreibt man Natrium salicylicum, wenn es sich um längern Gebrauch handeltp
}

Von Apotheker F. Hellwig, Baruth.

In die Apotheke des Unterzeichneten kam z,u Anfang Novembers ein Recept von einem Cölner Arzte, lautend:

R. Natr. salicylic. 20

Syr. flor. Aurantii 30

Aq. destillat. 250

S. Täglich drei bis vier Essloffel z. nehmen.

Zugleich war auf dem Recepte bemerkt: „Diese Mixtur soll oft wiederholt werden, und zwar mit Abwechslung in den Syrupen, 
oder es kann auf Wunsch der Patientin das Natr. salicyl. in Oblate oder anderer Form gegeben werden." Ich fertigte die Mixtur in dem Glauben an, dass die Repetitionen wohl nicht verlangt werden wïrden, gab auch noch $10 \mathrm{~g}$ in 10 Limousin-Oblaten und $10 \mathrm{~g}$ in 10 Gelatine-Kapseln mit. Nach nicht langer Zeit wurde die Mixtur nochmals verlangt. Die Dame liess mir sagen, die grossen Limousin-Kapseln nähmen sich sehr schwer ein, ${ }^{1}$ besser die GelatineKapseln, aber das Brennen, das nach der Auflösung der Umbüllung vom Magen aufsteigend bis in den Mund fühlbar sei, wäre doch noch weit unangenehmer, als der fad süsse Nachgeschmack der Lösung, den sie mit den feurigsten Menzer'schen Griechen-Weinen nicht zu unterdrücken im Stande sei. Ich nahm, um mit dem Saft zu wechseln, beim zweiten Male Syr. Cortic. Aurantii. Nach etwa einer Woche verlangte die Dame die 3. Flasche, aber ja mit dem Geschmack der 2. Flasche, und siehe die Dame verlangte nach und nach 7 Flaschen à $20 \mathrm{~g}$ Natr. salicylicum. Ich sprach meine verwundernde Hochachtung vor solch seltener Energie aus und erfuhr, das mache sich ganz leicht, wie sie durch Zufall ermittelt hätte. Weil Vino dinette und Maurodaphne den lätschigen Geschmack nicht zu dämpfen vermochten, griff die Dame nach Rum, den der Professor in Cöln auch angerathen hatte, vergriff sich aber und nahm einen Theeloffel roll salzhaltigen Cognacs, der sonst zu Einreibungszwecken diente. Und siehe, diese zugleich salzige und das Cognac-Arom führende Flïssigkeit tilgte schneller, als alle Süssweine etc., den wohlbekannten, widrigen Geschmack. Von da ab hat die Dame nur den Salzcognac nach der Arznei getrunken, und, um sich des ungewöhnten

1) Schreiber dieses hat sich schon oft darüber gewundert, dass die Fabrikanten von Oblate - Capseln noch nicht auf den sehr naheliegenden Gedanlen gekommen sind, die Form der Oblaten-Capseln don Capsules gelatineuses ähnlich „eiförmig " zu machen. Nur besonders ausgoweitete Schlünde vermögen die $1 \mathrm{~g}$ Chinin haltenden, grossen radförmigen Limousins No. 1 herunter zu bringen. Das doutsche Fabrikat ist zwar nicht ganz so flach, als die Iimousin-Capsel, dagegen sind die Ränder breiter und sind sie meist aus dünner, sehr poröser Oblate gearbeitet, so dass die bitteren Stoffe, die darin genommen werden sollen, durchstäuben, was man doch oigentlich nicht beabsichtigt, wenn man ein Medicament in Capseln giebt. Ich glaube, alle Collegen würden es als grossen Fortschritt begrüssen, wenn sich ein Fabrikant darauf legen wollte, eiförmige Capseln aus solider Oblate und mit schmalem Rande darzustellen, kosten diese Art auch das Doppelte der jetzigen recht unvollkommenen Oblaten-Capseln.

Arch. d. Phanm. XXIV. Bds. 2. Bft. 
Brennens im Munde, nach dem Cognac, bald zu erwehren, ein Stückchen guten Cacaos nachgegessen. Auf die Weise verbrauchte sie in 2 Monaten $150 \mathrm{~g}$ des salicylsauren Natriums und meint, wenn der Cölner Arzt noch weiteres Einnehmen für gut finde, sie bereit sei nochmals ein Quantum, wie das obige zu nelımen, da sie sich recht wohl darnach fühle.

Verf., der leider eine reiche Erfahrung hinter sich hat im Einnehmen von Salicylsäure, hat sich selust davon überzeugt, dass

1) der Syr. Cortic. Aurantii der einzig geeignete Saft ist, um den widerlichen Geschmack des Mittels erträglicher zu machen, und

2) dass Salz-haltiger Cognac besser, als alles andere, den anhalhaltend süsslich, ekelhaften Nachgeschmack zu tilgen im Stande ist. Fr bittet seine Collegen, die gleich ihm an rheumatischen Anwandlungen leiden, sich von der Richtigkeit des Mitgetheilten überzeugen zu wollen.

\section{Zur Prüfung des Bittermandelwassers.}

Von Dr. W. Kubel, Apotheker.

Ein sehr brauchbares Magnesiapräparat für die Prüfung des Bittermandelwassers erhält man schnell auf folgende Weise.

$25 \mathrm{~g}$ reine verdünnte Essigsäure werden in einem passenden Schälchen oder Kölbchen mit etwa $100 \mathrm{~g}$ destillirtem Wasser versetzt, $10 \mathrm{~g}$ möglichst chlorfreie gebrannte Magnesia zugefügt (ein geringer Kohlensäuregehalt schadet hierbei nicht), und unter Umrühren die Milch zum Kochen erhitzt. Nach wenigen Minuten hat sich die nicht gelöste Magnesia in ein schleimiges Hydrat verwandelt, wodurch die Mischung breiartig wird. Man fügt soviel Wasser hinzu, dass das Gewicht der Mischung etwa $150 \mathrm{~g}$ beträgt und bewahrt sie in einem nicht zu enghalsigen Gefüsse, welches durch Glas oder Korkstöpsel zu schliessen ist, auf. Das Präparat ist eine alkalisch reagirende Lösung von basisch essigsaurer Magnesia mit darin suspendirtem Magnesiahydrat und enthält rom letzteren etwa 7 Proc. Die Prüfung des Bittermandelwassers mit Hilfe dieses Magnesiapräparates, das vor dem Gebrauche kräftig umzuschütteln ist, geht sehr schnell vor sich, und beruht die schnelle Wirkung gewiss mit auf dem Gehalte an gelöstem basischen Magnesiumacetat. Da die gebrannte Magnesia meist nicht ganz chlorfrei ist, so kann man dieselbe vorher auswaschen, oder aber, was immer zu empfehlen ist, auch bei dem 